\title{
The Mathematical Formatting of How Climate Change Is Perceived
}

\author{
Teachers' Reflection and Practice
}

Lisa Steffensen, Rune Herheim and Toril Eskeland Rangnes

\begin{abstract}
This chapter concerns how three teachers in lower secondary school include climate change in school mathematics. Data was collected over a one-year period, where the teachers organised several teaching activities such as fieldwork, posters, contribution to an exhibition, and dialogue and debates, to facilitate students' critical mathematics competences through working with climate change. We apply a teacher perspective and focus on the role mathematics can play in formatting the understanding of climate change. A formatting power of mathematics is identified at three levels: (1) in teachers' meta-reflections, (2) when the teachers use mathematics to format students' understanding, and (3) when teachers facilitate students' awareness of the formatting power of mathematics. The findings suggest that a complex issue like climate change brings forth an awareness of the formatting powers of mathematics.
\end{abstract}

\section{Keywords}

teachers' reflection and practice - mathematical formatting - climate change - uncertainty - research partnership

Climate change can be regarded as one of our society's greatest challenges, with profound consequences and a high degree of complexity. ${ }^{1}$ The Intergovernmental Panel on Climate Change (IPCC) (2018b) stated in a press release that "limiting global warming to $1.5^{\circ} \mathrm{C}$ would require rapid, far-reaching and unprecedented changes in all aspects of society" (p. 1). These changes, or the consequences of not making them, can potentially have a huge impact on citizens' everyday lives. The IPPC report concerning global warming of $1.5^{\circ} \mathrm{C}$ (2018a) was written by experts from different fields, in which 91 lead authors

(C) LISA STEFFENSEN, RUNE HERHEIM AND TORIL ESKELAND RANGNES, 2021 
and 133 contributing authors accessed more than 6 , ooo scientific publications. The IPCC reports over the years have been influential (e.g., on the Paris agreement) and have received much public attention. Some have disputed the science provided by the IPCC, such as by The Nongovernmental International Panel on Climate Change (NIPCC). The NIPCC 2 argued that the IPCC is "politically motivated, and predisposed to believing that climate change is a problem in need of a UN solution."

An understanding of climate change depends largely on scientific and mathematical knowledge. For instance, our understanding of future climate scenarios is to a large extent based on mathematical climate models. Thus, mathematics, or the ways that mathematics is used, contributes to the formatting of how future climate change is understood. Considering mathematics as a formatting power in society is in line with Skovsmose's (1994) argument that "mathematics has an important social influence; it follows that to understand this formatting power becomes an essential aspect of critical mathematics education" (p. 207).

Lloyd and Winsberg (2018) underlined that it is vital to understand the conceptual and philosophical foundations of climate models in order to make wellinformed judgments on how to act towards climate change. They discussed an example in which Christy (2016), an expert on satellite climate data, showed a graphical discrepancy between global mid-tropospheric temperature models and measurements done by satellites and weather balloons. Christy gave testimony to the United States Congress where he highlighted this discrepancy by using different graphs. His graphs are widely used by media and political and scientific communities (Lloyd \& Winsberg, 2018). Nuccitelli (2016) referred to Christy's graphs as the Republicans' favourite climate charts, and the graphs appear on several climate sceptic websites, such as in a blog post by Hamlin (2016). However, several researchers (e.g., Santer et al., 2008), have discredited Christy's discrepancy between models and observations by using statistical argumentation. For instance, Schmidt (2016), a climate modeller at NASA, argued in a blog post that the graph presented by Christy was misleading due to "incomplete model spread, inconsistent smoothing, no structural uncertainty in the satellite observations, weird baseline." These are all arguments that concern the methodological and mathematical choices made when making the graphical representation. Schmidt presented a graph that showed how the climate model projections are trustworthy, by using satellite observations and a different analysis.

The graphs from Christy (2016) and Schmidt (2016) offer two different representations of reality, based on mathematical choices and methodology. The question is then, which representation do policy-makers and citizens use to 
develop their understanding of climate change, and subsequently, to take action? Lloyd (2018) highlighted how data and observations can be "laden with assumptions and theory" (p. 138). With reference to Christy's (2016) example, Lloyd (2018) argued that "it now appears that the models were mostly right and the early data were mostly wrong, and therein lies an interesting story about data and their relations to scientists, models, and reality" (p. 138).

Kingan (2005) argued that incorporating social advocacy in mathematics education could include involvement in pressing real-world issues like climate change. She exemplified this idea by using three graphs that showed the amount of $\mathrm{CO}_{2}$ in the atmosphere (the Keeling curve), a comparison of $\mathrm{CO}_{2}$ and temperature, and a reconstruction of surface temperature over the last 1,ooo years. The latter graph is named "the hockey stick graph" due to its resemblance in shape to a hockey stick, and played an important role in an IPCC report (2001) about global warming and abrupt temperature rise. Kingan (2005) suggested that an understanding of functions, graphs, and scientific methods could "motivate students to study mathematics and understand, and potentially act upon, some of the controversial issues in the news" (p. 242).

Climate change involves competencies from several scientific fields, political and economic expertise, and skills in making value and judgment calls. Nordén (2018) underlined that some researchers on education for sustainable development focus on a transdisciplinary approach rather than a subject-oriented approach, in order "to support holistic learning of complex issues" (p. 663). Teachers in her study considered transdisciplinary approaches challenging, and Nordén argued that a better understanding of how teachers and students can work with complex and challenging issues in the classroom would help develop competencies in decision-making on these urgent issues.

Barwell $(2013,2018)$ highlighted that mathematics is involved and intertwined in many aspects of climate change. Mathematics provides technology that can affect the climate, and it is important in order to understand, describe, and predict future climate changes. Communication about climate change is to a large extent done with numbers and graphs. Barwell therefore argued that mathematics educators need to be engaged in climate change because of the extensive use of mathematics, and that students need to learn to reflect on the role that mathematics can play in climate change. He suggested Critical Mathematics Education ( $\mathrm{CME}$ ) as a theoretical perspective, as a way of engaging students as critical citizens. Furthermore, Barwell (2018) argued, in line with Skovsmose (1994), that to identify what shapes our society is an important part of being critical citizens. Barwell particularly highlighted the importance of identifying what shapes our understanding of climate change, to identify the mathematical formatting of climate change. 
How can mathematics education facilitate students' abilities to identify the role mathematics plays in the world? Inspired by this question, we investigated three lower secondary school teachers' choices and arguments for when they include climate change issues in their mathematics and natural science teaching. We focus on identifying the potential for facilitating students' awareness and understanding of the formatting power of mathematics.

Teaching mathematics in the context of climate change brings challenges and possibilities beyond teaching statistics and functions without a real-life context, and hence also a different theoretical perspective. Barwell (2018) argued that "critical mathematics education can offer a perspective with which to conceptualise how mathematics teaching and learning might educate future citizens" (p. 145) when discussing mathematics education for environmental sustainability. In this chapter, CME constitutes the main theoretical perspective for analysing and discussing the data. First, we introduce смE. Then, we present three key concepts within critical mathematics education, namely the formatting power of mathematics, uncertainty, and being critical citizens.

Several mathematics education researchers have explored different directions within CME, such as ethnomathematics (D'Ambrosio, 2007), pedagogy for dialogue and conflict (Vithal, 2003), and social justice (Gutstein, 2012). Of particular interest for this chapter is the work of Skovsmose (1994), who promoted a critical mathematics education in which students reflect on how mathematics can format their life. He described critical mathematics education in terms of a concern: "To address social exclusion and suppression, to work for social justice in whatever form possible, to try open new possibilities for students, and to address critically mathematics in all its forms and application" (2014, p. 116). The use of mathematics in climate change issues concerns social justice, both directly and indirectly. Climate change is a global challenge, but affects people and nations differently. The consequences of climate change are not always distributed fairly. It is not socially just when farmers lose their livelihood and people have to move from their homes, while $\mathrm{CO}_{2}$ polluters can carry on doing business as usual. As Barwell (2018) highlighted, mathematics is a crucial part of how we understand, describe, predict, and communicate about climate change, and it is therefore important to consider mathematics as an integrated part of challenges such as the economic impact worldwide, and the ethically and socially unjust situations connected to climate change. Addressing mathematics critically, as described by Skovsmose (2014), within 
a climate change context, can affect how people understand and act towards climate change.

\subsection{The Formatting Power of Mathematics}

Skovsmose (1994) introduced the notion of the formatting power of mathematics as a power that can shape our society. He asked: "Could a science like mathematics (formal or not) become not only interpretative but also formative?" (p. 42). Can mathematics format our understanding of climate change and our behaviour towards it? Can mathematically based choices made by professionals such as climate modellers, mathematicians, graphical designers, journalists, or teachers format our understanding and behaviour? By the formatting powers of mathematics, we understand how mathematics can format our society, and how people's intentional and unintentional use of mathematics can format our understanding and behaviour. Hauge and Barwell (2017) argued that when models of weather systems are "built into the fabric of society ... the mathematical models that drive them no longer describe reality, they become part of reality - they become prescriptive" (p. 28). Barwell (2013) used the expression "the mathematical formatting of climate change" with reference to Skovsmose's (1994) concept of the formatting power of mathematics. Barwell argued that climate change is operationalised through science, mathematics, technology, and by climate model projections in particular. Without mathematically based climate models, it would be difficult to identify and become aware of future challenges, because most qualified predictions and forecasts somehow involve mathematics. Furthermore, people's actions toward predicted scenarios are also being formatted, such as by choosing to eat less or not eat meat, commuting by public transport, or by reducing flights. Similarly, mathematics can format the understanding of climate change, how it is perceived, and what actions are taken towards it. Skovsmose (1994) discussed the process when mathematics goes from being descriptive to becoming prescriptive, by arguing that mathematics not only provides descriptions; it also provides "models for changed behaviour. We not only 'see' according to mathematics, we also 'do' according to mathematics” (p. 55).

\section{$1.2 \quad$ Uncertainty}

The Organisation for Economic Co-operation and Development (OECD) (2016) highlighted uncertainty as "a phenomenon at the heart of the mathematical analysis of many problem situations" (p. 72) in their Programme for International Student Assessment (PISA) 2015 report. Funtowicz and Ravetz (2008) argued that when "facts are uncertain, values in dispute, stakes high and decisions urgent" (p. 365), there is a need for what they call post-normal science. 
They regard climate change as such a challenge, and suggest an approach that goes beyond the traditional expert-policy regime in which experts provide solutions and politicians act according to their advice. Funtowicz and Ravetz discuss how climate change could involve an extended peer community consisting of ordinary citizens, such as representatives from interest-based organisations. An important part of such involvement will often include values and uncertainty. Hauge and Barwell (2017) reflected on how mathematics education can prepare students to contribute in these extended peer communities. They highlight three kinds of uncertainties from post-normal science: technological, methodological, and epistemic uncertainty. While the first two types of uncertainty can be addressed by applying mathematical and/or technological skills, Hauge and Barwell emphasise that epistemic uncertainty arises "from lack of knowledge, information or suitable methods, or the lack of awareness of some features of the situation" (p. 29).

With regard to climate change, there is still much to learn. In the IPCC report about global warming of $1.5^{\circ} \mathrm{C}$ (IPCC, 2018a), they emphasised the knowledge gap and included detailed descriptions of methodologies and key uncertainties. Although the IPCC recognises and communicates uncertainties, these reports have a huge formatting power and impact on society. The reports provide scientific information that nations use when developing climate policies that, in turn, affect people's everyday life. It is therefore imperative to critique the content of these reports, and the subsequent political actions. However, such critique has to be informed and well-founded. If not, it amounts to little more than dismissing science. In public and political debates, uncertainty is often connected to lack of knowledge, a subject poorly understood, as a weakness, and that scientists "do not know anything about a topic, just because they do not know everything about it" (Corner et al., 2012, p. 464). It can therefore be argued that one has to wait for more certainty before acting. In that sense, uncertainty becomes a formatting power on its own. It is therefore crucial that citizens learn about uncertainties in order to be able to reflect on different types of uncertainty as well as other aspects like precautionary principles. Hauge and Barwell (2017) connected epistemic uncertainty to Skovsmose's concept of reflective knowing, and argued that this is an important competency for citizens in an extended peer community. Skovsmose (1994) defined the notion of reflective knowing as "the competence needed to be able to take a justified stand in a discussion of technological questions" (p. 101). He underlined how mere mathematical or technological skills are insufficient, and emphasised that other aspects, such as sociological and ethical considerations, norms and values, need to be a part of how students reflect. Dealing with the challenges of climate change requires citizens to not only consider scientific 
knowledge, but to understand this as integrated with ethical and economic aspects. Skovsmose emphasised that reflective knowing is crucial for acting as a critical citizen, which brings us to our last key concept.

\subsection{Being Critical Citizens}

In today's society, where citizens are surrounded by a massive amount of information on complex matters, there is a need for citizens to be critical and reflective. With regard to climate change, much of this information involves scientific literacy. The OECD (2016) defined scientific literacy as the ability "to engage with science-related issues [...] as a reflective citizen" (p. 13), with competencies to explain phenomena, evaluate and design scientific enquiry, and interpret data and evidence scientifically.

Presenting and understanding climate change information also requires mathematical literacy: "an individual's capacity to formulate, employ, and interpret mathematics in a variety of contexts" (Organisation for Economic Cooperation and Development, 2016, p. 13). Mathematical literacy goes beyond mastering certain algorithms or procedural knowledge, and entails an emphasis on mathematics within a context. Furthermore, the OECD (2016) highlighted how an important part of mathematical literacy is to "assist individuals to recognise the role that mathematics plays in the world and to make the well-founded judgments and decisions needed by constructive, engaged and reflective citizens" (p. 13). The OECD's specifications on mathematical literacy connect with Skovsmose's (1994) formatting power of mathematics through the recognition of the role mathematics plays in society. However, neither of the definitions explicitly emphasise the role of being critical. Barwell (2013) problematised parts of the perspective on mathematical literacy presented by the OECD by arguing that "the general orientation is to the use of mathematics to interpret information and solve problems, rather than for critique" (p.6).

When discussing scientific literacy in the PISA 2015 framework, the OECD (2016), highlighted that new curriculum models do not focus "on producing individuals who will be 'producers' of scientific knowledge, i.e. the future scientists; rather, it is on educating all young people to become informed, critical users of scientific knowledge" (p. 18). Similar considerations apply for mathematics curricula. Very few students will become mathematicians who produce climate models, but all of them will need the skills to understand and critically assess such models in different ways. The recent focus in the media on "fake news" can be expected to generate increased interest in education on the importance of students being critical. The OECD (2015) underlined that although there seems to be a consensus on promoting critical thinking as a 
twenty-first century skill, "it is not clear how these skills can be made visible and tangible and articulated by teachers, students, and policy makers, especially as part of the curriculum" (p. 3) . For instance, what does it really mean to enable students' critical thinking within mathematics education, and, in particular, in the context of climate change? In science, there is a tradition of acknowledging the importance of a critical perspective for research, including the generation of hypotheses and theories. In the climate change debate, it is often highlighted as important to think critically about claims and arguments. Interestingly, being critical is also important for proponents of views that differ from the scientific consensus on climate change, such as those who reject the human impact on climate change.

From a mathematical perspective, it should be underlined that being critical does not mean rejecting scientific results. On the contrary, being critical can strengthen science by enabling students to recognise that uncertainties involved in climate models or climate observations are a natural part of mathematics and science. Similarly, emphasising that students (and teachers) learn to recognise and identify the role mathematics can play in formatting our society does not mean that the formatting power of mathematics is something that should be rejected, or in other ways be diminished (although that might be the case in some situations). Rather, it is about raising an awareness of the formatting power of mathematics - as Skovsmose (1994) puts it: "Mathematics has an important social influence; it follows that to understand this formatting power becomes an essential aspect of critical mathematics education" (p. 207).

Three teachers (Kim, Max, and Tim) and a researcher (Steffensen) established a research partnership to explore ways to facilitate students' critical mathematics competencies. In this chapter, we look, in line with Skovsmose (1994), at an awareness and understanding of the formatting power of mathematics as a key part of critical mathematics competency. The research partnership lasted for about a year, and consisted of seven partnership meetings, 42 lessons, a fieldwork activity, and participation in an energy exhibition. The research partnership meetings were a collaborative space for planning and reflecting on how the lessons could be done and had been done. These meetings were audio recorded while the lessons were both video and audio recorded. Kim and Tim had one grade ten class each, Max had two grade ten classes, and there were approximately 30 students in each class. The teachers were experienced mathematics and natural science teachers, and they taught the students in both 
subjects, but the observation only took place in the mathematics lessons. The teachers' written notes such as PowerPoint slides and handouts to the students served as additional material.

In order to identify the potential for facilitating students' awareness and understanding of the formatting power of mathematics, we investigate examples from three contexts: (1) the teachers' introductions to climate change and mathematics, (2) the teachers' meta-reflections when planning the fieldwork activity, and (3) the teachers' choices regarding a quiz made for the energy exhibition.

In their introductions, the teachers presented the topic of climate change and relevant mathematics to the students by sharing some of their own thoughts on the topic, as well as engaging the students to share their thoughts. We discuss an example from Max's introduction that serves as an example of how the teachers connected climate change issues to the curriculum.

In the examples from the research partnership meetings, the teachers are planning a fieldwork activity in which the students should measure climaterelevant data (such as $\mathrm{CO}_{2}$ and temperature of seawater) and do a fieldwork report. We have chosen to discuss some of Kim's utterances because they provide interesting insights into the teachers' reasoning and reflections underlying the fieldwork activity.

The energy exhibition was a gathering in which teachers and students from four different schools attended and presented energy-related topics to the public and to the local business community. The teachers and students made posters and a quiz as their contributions to the exhibition. We focus on the quiz, because the differences between the teachers' quiz questions illustrate well some of the choices the teachers had to make, such as choosing between different climate graphs. Although the researcher had a participatory role in the research partnership meetings, the teachers designed the lessons and activities, both collaboratively and individually.

The teachers' choices and utterances are our units of analysis. The choices and utterances presented in this section are selected because they represent distinct examples of how students' understanding of the formatting power of mathematics can be facilitated in a climate change context and they illustrate well some of the challenges teachers face in this respect. The data were transcribed, coded, and categorised by using NVivo. The coding resulted in four main categories, two of which were relevant for identifying the potential for facilitating students' awareness and understanding of the formatting power of mathematics: climate change related utterances (e.g., discussing $\mathrm{CO}_{2}$ and its impact on climate change), and critical mathematics competency utterances. Utterances associated with the formatting power of mathematics were 
identified in the meetings, lessons, and activities, and emerged as one of the sub-categories of critical mathematics competency. As a part of identifying how students' awareness and understanding about the formatting power of mathematics can be facilitated, we analysed utterances where the teachers and students reflected on how graphs, numbers, and models could affect people's perception of reality. Questions like, "How does understanding of climate change come about?," "What is hidden?" and "What is taken for granted?" were used as support in the analysis process.

Critical Mathematics Education and Climate Change in the Three Classes

In the following, we first discuss an example when Max introduced the project to the students. We then focus on teachers' meta-reflections by discussing two of Kim's utterances regarding the fieldwork planning, and finally, we discuss Max's and Kim's choices for the quiz.

\subsection{The Teachers' Introductions to Climate Change and Mathematics}

In their introductions, the three teachers expressed several goals for the lesson, such as introducing the topic of climate change and mathematics, inviting the students to contribute their ideas to what climate change in the mathematics classroom can look like, and introducing some basic climate change concepts like the difference between climate and weather. The teachers expressed concerns regarding the abstractness of climate change and mathematics. Max therefore decided to make some slides as an introduction, to point out links between mathematics and climate change.

In the first slide, Max argued for the purpose of mathematics as described in the curriculum by writing: "Active democracy requires citizens who are able to study, understand, and critically assess quantitative information, statistical analyses, and economic prognoses. Hence, mathematical competence is required to understand and influence processes in society." This utterance is a direct quotation from the mathematics curriculum (Ministry of Education and Research, 2013), and both the terms "understand" and "critically assess" are explicitly stated. The emphasis on not only understanding but also on critically assessing is highlighted as important in the curriculum and something that Max explicitly displayed to her students. The curriculum quote was accompanied by a picture of a polar bear clinging to a small piece of melting ice (see Figure 9.1).

A polar bear and melting ice has, for many, become a symbol of climate change (Born, 2019), and the picture that Max used drew the students' attention 


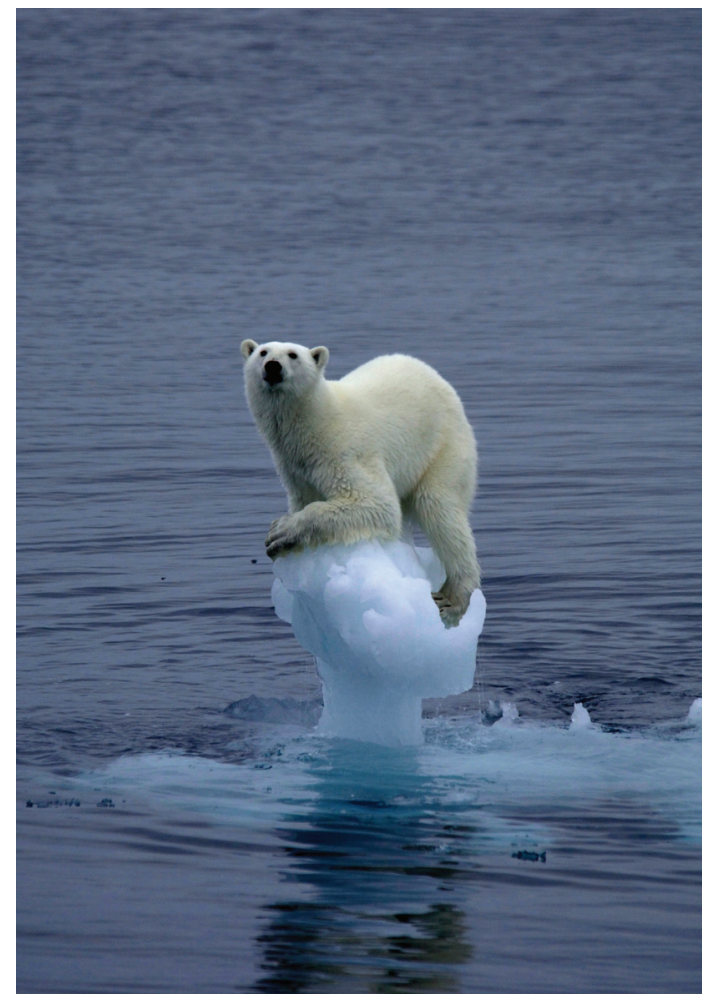

FIGURE 9.1

The picture on Max's first slide (photograph by Arne Naevra)

towards climate change challenges. When Max used this symbol of climate change, she positioned the mathematics with a clear connection to the active democratic purpose of mathematics. Such positioning can be interpreted as an action to motivate students to engage and influence processes in society by saving the polar bears from extinction due to climate change.

One of the other slides required participation from students, with the headline "Reflections." It contained the following questions: "What do you know about climate and challenges related to this? Take two minutes to think individually, and then discuss with a learning partner." The students provided written answers, and there was a plenary discussion at the end. One group provided the following written statement:

The climate is getting hotter because of increased $\mathrm{CO}_{2}$ emissions in the atmosphere. The increased heat leads to the risk of melting the polar ice, which will cause massive floods and climate change. There is therefore an international goal that the average temperature should not rise by more than $2^{\circ} \mathrm{C}$. It is therefore relevant to discuss the question whether we should open a new oil field or not. 
The students based their arguments on scientific and mathematical knowledge such as "increased $\mathrm{CO}_{2}$ emissions" and "increased heat leads to the risk of melting the polar ice." They went on by arguing that as a consequence of the $2^{\circ} \mathrm{C}$ temperature target, the Norwegian government should "discuss the question whether we should open a new oil field or not." However, they did not provide any written discussion concerning the claim that the temperature should not rise by more than $2^{\circ} \mathrm{C}$, and did not show that they could "critically assess quantitative information" (which was stressed in the first slide). Although Max emphasised evaluating arguments and evidence in a mathematical way, it was not documented that any of the students explicitly did this in this first lesson. The $2^{\circ} \mathrm{C}$ target appears to be taken for granted and the formatting power of numbers and mathematics is not identified, discussed, or reflected upon by the students. As Skovsmose (1994) and Hauge and Barwell (2017) argued, the global $2^{\circ} \mathrm{C}$ temperature target becomes a number built into the fabric of society and no longer just describes reality; it prescribes reality.

Frisch (2018) highlighted that the $2^{\circ} \mathrm{C}$ target is based on precautionary principles and political consensus, more than on strictly scientific knowledge. For instance, he referred to an interview where John Broome, a philosopher and climate change author, who said that the $2^{\circ} \mathrm{C}$ target "has just been pulled out of the air" (Frisch, 2018, p. 415). Although the students did not critique the $2^{\circ} \mathrm{C}$ target, one might say that the students are taking a stand on social justice matter through mathematics, in line with Skovsmose's (2014) definition of CME, by critically engaging in what the Norwegian society should look like. Although there are political forces working towards stopping further oil and gas exploitation, the present situation in Norway is that the government continues with opening new search fields for oil and gas. By raising the controversial political question of whether to open new oil and gas fields, the students are reflecting on and challenging the present Norwegian policy. It is a big question to raise, taking into consideration that the Norwegian economy is largely dependent on income from oil and gas, and a reduction in income would generate major consequences for the students and for Norwegian society. The $2^{\circ} \mathrm{C}$ target then has a formatting power when the students prescribe which actions the government should take (see Skovsmose, 1994).

\subsection{The Teachers' Meta-Reflections When Planning a Fieldwork Activity}

During the partnership meetings, the teachers discussed a wide variety of issues, including which topics that might be relevant to include in the lessons and how politicians make decisions on climate change-related issues. When reflecting on historical temperatures, on statistics, and on techniques used to measure the Earth's temperature, Kim said the following ( $\ldots=1-3$ seconds pause): 
Measuring uncertainty is also a bit interesting, if we can focus on that. Because ... they have measurement stations round about. There are discussions on where they are located. For instance, near big cities, do urban areas affect the temperature, for example? Then, the temperatures have to be adjusted by a machine with regard to this. Is it most relevant to use this [ground measurements close to cities], or is it more relevant to use the temperatures in balloons that you send into the atmosphere ... and then measure the temperature? What gives the best picture? And how many measurement stations do you have in that area and how many do you have in that area? Take Antarctica. There are not many measurement stations there ... and that is a huge area. And elsewhere as well. This could be interesting to discuss, in terms of uncertainty, and what affects the results.

Kim expressed an interest in uncertainty related to measurement. He asked "if we can focus on that," which can be regarded as a proposal to the other participants that measuring uncertainty is a relevant topic to explore. All the teachers later included Kim's proposal in the fieldwork activity. When Kim designed the fieldwork activity, he deliberately aimed for bringing about differences between the students' measurement results by asking the students to measure several times and with multiple instruments (see Figure 9.2). He included several questions in order to make the students reflect, discuss, justify their measurements, and help them decide which temperature was the most representative and should thus be included in their report. Kim's last question in Figure 9.2 extended the students' attention from their seawater measurements to the more general measurements of the Earth. The focus on measurement differences can be considered as a part of enabling students to deal with uncertainty, as a preparation to participate in an extended peer community by learning to cope with uncertainty (Hauge \& Barwell, 2017).

Kim continued by saying "there are discussions" regarding the location of measurement stations. The discussions Kim refers to can be linked to some of the controversies connected to temperature changes and climate change. He points to stations "near big cities," and asks if "urban areas affect the temperature." The heat island effect is sometimes used as an argument in the climate change debate (e.g., Sherrington, 2018). The IPCC (2013) described and discussed this phenomenon and the uncertainty related to this, and concluded that these urban affected temperatures are not likely to have a significant impact on global land warming trends. Similarly, Oreskes (2018) emphasised that the Berkeley Earth Surface Temperature Group found that "the observed warming cannot be explained away this way" (p. 46) (referring to the heat island effect). 


\begin{tabular}{|c|c|c|c|c|c|}
\hline SEAWATER & & & & & \multirow{5}{*}{$\begin{array}{l}\text { Why do you think you should take three } \\
\text { measurements and calculate the average? } \\
\text { - What are possible sources of error? } \\
\text { - How accurate do you consider your } \\
\text { measurement results to be? Justify the answer. } \\
\text { Discuss how you think the global average } \\
\text { temperature of the Earth is measured. }\end{array}$} \\
\hline & \multicolumn{4}{|c|}{ Measurements } & \\
\hline Method & 1 & 2 & 3 & Average & \\
\hline Digital & & & & & \\
\hline Analogue & & & & & \\
\hline
\end{tabular}

FIGURE 9.2 Kim's measurement table and four of the questions

However, Oreskes argued that this potential source of error is emphasised by some opponents. Kim's suggestion to include measurement uncertainties in teaching could serve as an opportunity for the students to explore potential sources of error in, for example, statistics, graphs, and models.

Kim then problematised that "the temperatures have to be adjusted by a machine." The machine reference can be interpreted as pointing to the black box problem where some input magically is transformed into some output, where computers handle mathematical calculations and models by themselves. Skovsmose (1994) emphasised situations where human-made decisions were hidden behind technology as important for identifying formatting powers. When these students decided on the most representative temperature measurement, they knew that other measurements could be just as relevant, and such knowledge is potentially transferable to other situations as well.

Kim compared two measurement techniques by asking if "it is most relevant to use this [ground measurement closes to cities], or is it more relevant to use the temperatures in balloons that you send into the atmosphere?" The temperatures from different methods can differ, and give a different perceived reality to the public. Lloyd (2018) highlighted that in Christy's (2016) report, the measured satellite data was treated "as windows on the world, as reflections of reality, without any art, theory, or construction interfering with that reflection" (p. 143). Kim then asked, "What gives the best picture?" When scientists describe reality, it will always be a chosen representation. Different representations can give different impressions. Therefore, it becomes important to discuss how representations can (re)present different connections to reality, often depending on choices of a statistical or practical nature, such as when Kim designed the field report, asking for multiple measurements of the same quantity. He facilitated students' reflective knowing, as emphasised by Skovsmose (1994). When mathematical decisions and choices are involved in describing reality, the mathematics can take on a formatting role of how climate change is understood and perceived.

Kim continued to focus on measurement issues by questioning the number of measurement stations in different areas around the world: "Take Antarctica, 
there are not many measurement stations there ... and that is a huge area." There is a high density of ground measurements in populated areas, and few in more remote areas (Hijmans et al., 2010). Kim pointed out that the location of measurements influences the models and the extent to which the temperatures are regarded as high or low. Such choices influence the models, and the models influence how people understand the world. By emphasising how choices and models can influence people's perception of climate change, Kim provides an argument for the formatting power of mathematics.

Later on, the teachers discussed climate models. The researcher asked whether the students' attention was directed towards how mathematics could be used to influence them. Kim responded by referring to how politicians could be influenced:

Then they [the politicians] think that this is how it is ... they are told that it is like this. They really have no qualifications to say this or that. They just have to trust what the advisers and others say to them ... and then they must decide that this is the reality. [...] So, those who decide what society we are going to have, they are influenced by others who have decided that this is the way it is.

Kim started by pointing out that politicians "think that this is how it is," and emphasised that politicians' perceptions of reality are based on climate models. He continued by stating, "they are told that it is like this." Kim positioned politicians as passive recipients. Initially, he does not explicitly say how or by whom the politicians are told this, but later he refers to "advisers and others." In climate change issues, advisers typically are experts on climate change models and data. Kim's reference to such advisers can be regarded as an example of what Funtowicz and Ravetz (2003) referred to as an expert-regime. Kim then added, "they really have no qualifications to say this or that." Even though politicians are not experts on topics such as climate change, they still have to make decisions. When Kim claimed that "they just have to trust what the advisers and others say to them," he again referred to the hidden power of the experts and their models. Using the word "trust" suggests an emphasis on the power relations between politicians/decision makers and the experts/models. One side must rely on the other to make good decisions. This interpretation is strengthened by Kim's next utterance: "and then they must decide that this is the reality." Linking advisers, experts and their models, to how politicians perceive reality is another way of highlighting the hidden powers through which mathematics can format the society. 
Kim finished his arguments by emphasising even more the hidden powers that scientists and mathematicians potentially can have, by saying: "So, those who decide what society we are going to have, they are influenced by others who have decided that this is the way it is." This is in line with Skovsmose's (1994) argument that we not only see according to mathematics, we also do according to mathematics. In climate change issues, experts act according to numbers and models, and in turn, decision-makers act according to experts' arguments on the climate and the economy. Mathematics can therefore format both understanding and action about climate change. When the researcher asked Kim about students' awareness of the formatting powers of mathematics, he referred to how politicians are influenced by experts. By pointing to how politicians can be influenced, Kim put in perspective how challenging it can be to facilitate students' understanding and awareness of the formatting power of mathematics.

\subsection{The Teachers' Choices Regarding a Quiz Made for an Energy Exhibition}

In this section, we provide examples of how the teachers' mathematical choices and their highlighting of certain topics relating to climate change potentially can format students' understanding of climate change. The examples come from the energy exhibition. The teachers had made a multiple-choice quiz, and the students asked participants at the exhibition to answer five quiz questions. The teachers had agreed in the partnership meeting that it could be interesting to ask questions that could surprise the participants. They said they wanted to generate engagement and discussions.

The teachers had three identical questions ( $\mathrm{Q}_{1}, \mathrm{Q}_{2}$, and $\left.\mathrm{Q}_{5}\right)$, but they chose to differ in two of the questions ( $\mathrm{Q}_{3}$ and $\mathrm{Q}_{4}$ ). Figure 9.3 shows Kim's quiz with correct answers indicated. Max chose to replace two of Kim's questions. Her argument for doing this was that although the questions and answers were sort of correct, they could give an incorrect impression of climate models and an increase in temperature.

Kim asked in the third question whether climate models correlate well with measured temperatures over the last 20 years. The focus is on the imprecision of climate models, and the correct answer according to the quiz was "very poorly." A graph that backed up this answer was shown on the back of the quiz. The graph appeared in Christy's (2016) United States Senate testimony and shows temperature changes predicted by 102 different climate models, and compares these with observed temperature changes measured by satellites and balloons. Lloyd (2018) explained how this graph was used to support the claim that climate models and observed data have discrepancies, and thus climate models 
Q1: Which greenhouse gas affects the temperature on the Earth the most?

a) $\square$ Carbon dioxide, $\mathrm{CO}_{2}$ b) $\mathbf{z}$ Water vapour, $\mathrm{H}_{2} \mathrm{O}$ c) $\square$ Methane, $\mathrm{CH}_{4}$ d) $\square$ Ozone, $\mathrm{O}_{3}$

Q2: How many temperature stations on the Earth measure temperatures used to calculate the atmospheric average temperature?
a) $\mathbf{x}$ about 6000
b) $\square$ about 50000
c) $\square$ about 400000
d) $\square$ about 1000000

Kim's Q3: How well do the climate models' temperature scenarios correlate with measured temperatures over the last 20 years?
a) $\square$ Very well
b) $\mathbf{x}$ Very poorly

Kim's Q4: How much has the Earth's average temperature increased since 1998 ?

a) $\mathbf{~}$ Almost nothing b) $\square$ approximately $1^{\circ} \mathrm{C}$ c) $\square$ approximately $2^{\circ} \mathrm{C}$ d) $\square$ approximately $4^{\circ} \mathrm{C}$ Q5: If power stations running on gas on Norwegian platforms are replaced by stations running on electricity via power cables from land, will that lead to less $\mathrm{CO}_{2}$ emissions from Norwegian gas?
a) $\square$ Yes
b) $\mathbf{x}$ No

FIGURE 9.3 Kim's quiz

are not trustworthy. To compare climate models with real observations is both important and a relevant part of scientific work. Kim's choice to focus on the uncertainties of climate models by focusing on the discrepancy displayed by this particular graph, could contribute to formatting students' (and quiz participants') opinions on climate change, by suggesting that projections from climate models are not trustworthy. This was also one of Max's arguments for replacing this question on her quiz. It is imperative to keep in mind that mathematical models can never be exact replications of reality; neither can the observations represent reality in a precise manner. Such discrepancies are important to acknowledge when comparing models with observations. As Corner et al. (2012) argued, just because scientists "do not know everything" about a topic does not mean they "do not know anything" about it (p. 464).

Kim could have chosen another graph, such as the graph made by Schmidt (2016) in Figure 9.4. Schmidt compared satellite observations with projections from climate models, and displayed a quite different picture from that implied by Christy's graph. In Schmidt's graph, the differences between the observed data and model projections diminish. Kim's claim in the quiz, that climate models correspond "very poorly" with measured temperatures, is erroneous according to this graph, because most of the observed data are within the extremities of the projections. Furthermore, by focusing on the comparison of measurements done by satellites (and weather balloons) in the midtroposphere, Kim highlighted measurements that show the most discrepancy with the climate models. Several other climate model projections are more in compliance with measured data. For instance, as summarised in an article 


\section{CMIP5 TMT vs. Satellite Observations}

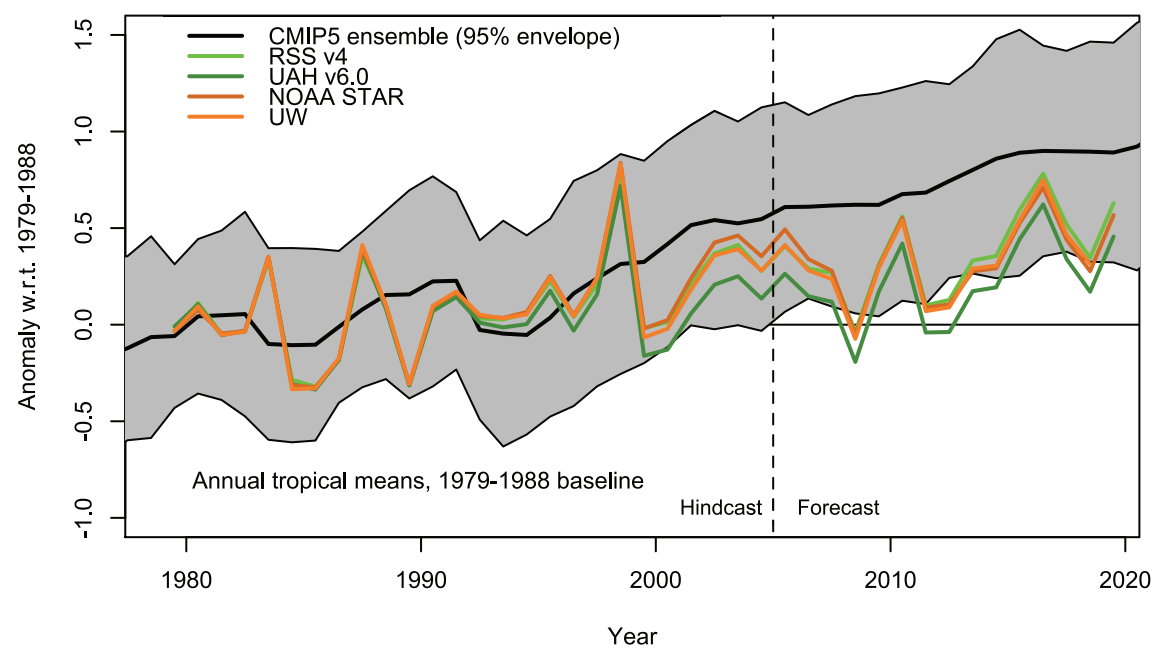

FIGURE 9.4 Schmidt's graph (2020, personal communication) - climate model projections versus satellite observation (for an older version of this graph, see Schmidt, 2016)

by Nuccitelli (2016), the temperature on the Earth's surface (see, for example, Mann et al., 2016), sea level rise (see e.g., Intergovernmental Panel on Climate Change, 2013), Arctic sea ice (Stroeve et al., 2012), and ocean heating (Cheng et al., 2015) are all examples where there is little discrepancy between measured observations and projections.

In the fourth question, Kim asked about the magnitude of the Earth's average temperature increase over the last 20 years. The correct answer was "almost nothing." The answer was justified by the graph in Figure 9.5. The graph emphasises small temperature changes over the last 20 years, without displaying any ordinate axis nor temperature levels. A similar focus can be seen in the framing of the question, by the choice of a relatively short timeline, the choice of distractors, the correct answer situated at one end of the scale, and the wording "almost nothing." Together, these two questions and graphs can influence the understanding of climate change in the sense that there is no increase in temperature and that climate models are not trustworthy. The mathematical-based choices of measurements, and graphs, can contribute to format society.

Max chose to replace Kim's third and fourth question with her own questions (see Figure 9.6). Max's questions concerned the Arctic sea ice level and sea level changes. The correct answer on the third question, $-36 \%$, was different from the distractors because it stood out by being considerably bigger 


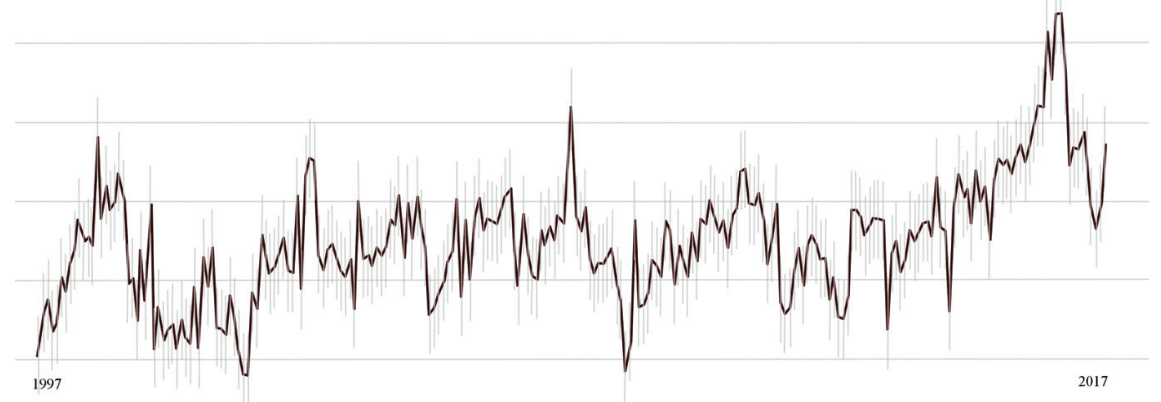

FIGURE 9.5 The temperature graph from the quiz, recreated from a graph in Watts (2017) (Source: Met Office)

Max Q3: How much sea ice was in the Arctic in 2016 compared to a normal level?
a) $\square+10 \%$
b) $\square$ equal
c) $\square-10 \%$
d) $\mathbb{x}-36 \%$

Max Q4: Satellite data indicate that the sea level had changed. How much has the sea increased in recent years?
a) $\square$ approximately 5 nanometers
c) $\square$ approximately $5.7 \mathrm{~cm}$
b) $\mathbf{X}$ approximately $3.4 \mathrm{~mm}$
d) $\square$ approximately $1.2 \mathrm{~m}$

FIGURE 9.6 The two questions Max used to replace two of Kim's questions (a normal level is the arithmetic average of recorded levels from 1961-1990)

and was not a multiple of 10. Max confirmed in a partnership meeting that she chose the distractors consciously in order to accentuate the severity of ice melting, in line with how she used the picture of the polar bear in one of her slides in the introduction to the students. By highlighting the correct answer in this way, Max could potentially influence the students' understanding of climate change in a way that focused on the big ice melting in Arctic.

The fourth question focused on sea level changes, and this question also contained big differences between the distractors (from nanometres to metres). However, the correct answer was in the middle $(3.4 \mathrm{~mm})$, and did not stand out to the same extent as the correct answer to the third question. Like Kim, Max chose to focus on one particular measurement method, the satellite data. These data have a timeline that starts in 1993. However, if Max had chosen another measurement method, such as coastal tide gauge records, the answer would have shown a smaller sea level increase $(1.8 \mathrm{~mm}$ instead of $3.4 \mathrm{~mm}$ per year $\left.{ }^{3}\right)$. Both methods do, however, illustrate a similar and increasing trend (see Figure 9.7). 

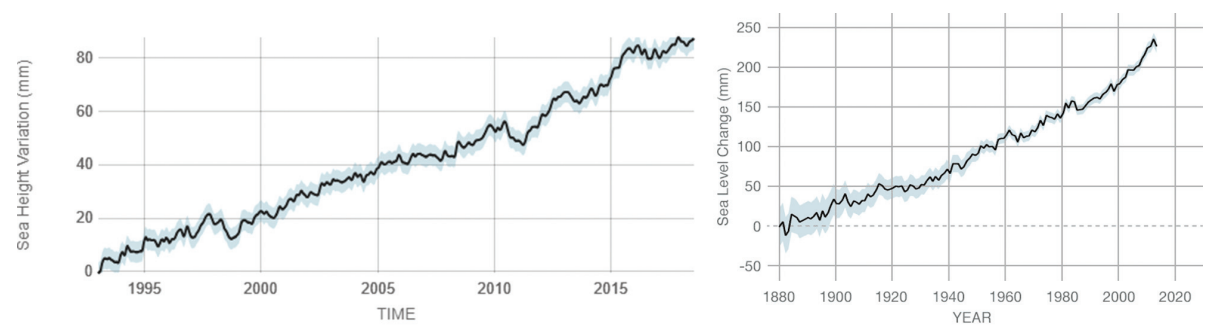

FIGURE 9.7 The graph to the left shows data from satellites with an annual increase of 3.2 $\mathrm{mm}$, while the graph on the right shows coastal tide records with an annual increase of $1.8 \mathrm{~mm}$ (Source: NASA, https://climate.nasa.gov/vital-signs/sea-level/, accessed 2018)

In line with Kingan (2005), Kim and Max incorporated a real-world issue like climate change in mathematics education. While Kim highlighted the uncertainties in climate models and the small increase in temperature, Max emphasised the large ice-melting and the increase in sea level. Their choice of numbers, distractors, and the focus of their questions, suggest that Max and Kim emphasised different perspectives on climate change. These choices can be more or less deliberate. A discussion between Max and Kim in a partnership meeting showed that Max did try, to some extent, to influence the quiz participants' views on climate change by deliberately leaving Antarctic out of the ice melting statistics (Steffensen et al., 2018). If teachers include climate change in their mathematics teaching, choices like this, whether they are deliberate or not, are worth reflecting on for the teachers themselves, as well as together with their students. Such discussions offer a fruitful arena for facilitating students' development of an awareness and understanding of the formatting power of mathematics.

\section{4}

\section{Concluding Comments}

In order to develop teachers' and students' competencies to identify the mathematical formatting powers of climate change, we need more knowledge about the existing awareness of the formatting power of mathematics in teachers' and students' work with climate change. Formatting powers of mathematics are identified in three contexts in the data: the teachers' introductions, their metareflections when planning a fieldwork activity, their choices regarding a quiz to an energy exhibition. In the first example, the teacher emphasised to the students the importance of being critical in order to understand and influence 
society. This is in line with the focus in the national curriculum on being able to critically assess quantitative information. Although the students were encouraged to critically assess quantitative information, it was not observed in the chosen example that the $2^{\circ} \mathrm{C}$ target was questioned. It could seem like they took it for granted.

In the second example, when the teachers planned the fieldwork activity, they discussed how the global temperature is measured, the different choices involved in such measurements, and the uncertainty connected to these methods. For instance, deciding whether to choose ground or atmospheric measurements is a human choice that could, from the teachers' perspective, shape how reality is perceived. Similarly, politicians' perceptions of reality and the foundation for making decisions rely on experts' models. In the third example, the teachers, more or less intentionally, used mathematics to influence the students' and the participants' understanding of climate change. They did this through their choices in making the quiz and through the way they used particular numbers and graphs to highlight different topics and perspectives regarding climate change. Society consists of individuals. Without individuals being influenced or using mathematics to influence others, one can argue that society will not be formatted. In this text, we have extended the formatting power of mathematics to include how mathematics can format individuals and how individuals can use mathematics as a tool to format others' understanding of reality, which consequently can impact society.

Regarding the measurement of the temperature of the Earth, new technology will make it possible to do measurements all across the world. However, there will still be choices to be made that involve scientific, technological, and mathematical questions, and complete "certainty" can never be achieved. These choices include deciding on an appropriate number of measurement stations; whether to use ground measurement or atmospheric measurements; deciding on the size of the heat island effect; or whether or not to include the ocean temperatures. The numbers and graphs showing global temperatures might seem appealingly easy for the public to conceive, but behind the mathematics, there are a number of choices not particularly visible or easily accessible for the public sphere.

Numbers and graphs are often used in public debates on climate change. Such data can be based on observations as well as predicted data from climate models, and both situations can contain different levels of uncertainty. However, if public debates make people think that the observed and predicted data cannot be trusted because of the element of uncertainty, then the element of uncertainty could lead to disengagement in climate change and distrust in 
mathematics, as well as format how climate change is perceived. Therefore, researchers, such as Hauge and Barwell (2017), have underlined that educating students to deal with different types of uncertainty can provide a greater understanding of how to deal with uncertainties of climate change. Furthermore, such uncertainties are not necessarily flaws that have to be corrected, but rather to be included as a natural part of scientific processes.

So, how can students' competencies to identify the formatting power of mathematics in a climate change context be facilitated? We identified challenges at different levels. Teachers need to develop an awareness about how mathematics is used in argumentation, as the teachers in this study did. They also need an awareness of how they themselves make use of the formatting power of mathematics in their teaching and facilitation for critical learning. Developing students' understanding and awareness of the formatting power of mathematics is anything but straightforward. Students need time and opportunities to experience how to be critical in constructive ways. There is a need for teachers and researchers to design research together, to explore possible teaching methods that can develop students' abilities to be critical and to recognise the formatting powers of mathematics. Working with measurements, modelling, or other mathematical topics connected to climate change is one possibility. The complexity of climate change can generate problems other than those found in more traditional mathematical tasks - problems that are more relevant for the real-life problems of society. Discussing uncertainty and evaluating argumentation can be a fruitful approach for students to learn how to use mathematics in their own argumentation, as well as to be critical about others' use of mathematics. The aim of being critical is not to make students reject mathematically based results from science. Rather, by recognising and discussing uncertainty in their own projects and in climate research, we believe the credibility of research can be increased through a more nuanced understanding, which is necessary if we are going to make changes for a sustainable future.

\section{Notes}

1 This chapter is an extended version of Steffensen, Herheim, and Rangnes (2018). A version of the chapter appears in Lisa Steffensen's (2021) doctoral dissertation.

2 http://climatechangereconsidered.org

3 The observed measurements are retrieved from Kartverket, the same source that Max used in the quiz question (https://kartverket.no/til-sjos/se-havniva/havniva/slik-maler-vihavnivaet). 


\section{References}

Barwell, R. (2013). The mathematical formatting of climate change: Critical mathematics education and post-normal science. Research in Mathematics Education, 15(1), 1-16. https://doi.org/10.108o/14794802.2012.756633

Barwell, R. (2018). Some thoughts on a mathematics education for environmental sustainability. In P. Ernest (Ed.), The philosophy of mathematics education today (pp. 145-16o). Springer. https://doi.org/10.1007/978-3-319-7776o-3_9

Born, D. (2019). Bearing witness? Polar bears as icons for climate change communication in National Geographic. Environmental Communication, 13(5), 649-663. https://doi.org/10.1080/17524032.2018.1435557

Cheng, L.-J., Zhu, J., \& Abraham, J. (2015). Global upper ocean heat content estimation: Recent progress and the remaining challenges. Atmospheric and Oceanic Science Letters, 8(6), 333-338. https://doi.org/10.3878/AOSL20150031

Christy, J. R. (2016). U. S. House Committee on Science, Space and Technology: Testimony of John R. Christy. https://docs.house.gov/meetings/SY/SYoo/2016o2O2/104399/ HHRG-114-SYoo-Wstate-ChristyJ-20160202.pdf

Corner, A., Whitmarsh, L., \& Xenias, D. (2012). Uncertainty, scepticism and attitudes towards climate change: Biased assimilation and attitude polarisation. Climatic Change, 114(3), 463-478. https://doi.org/10.1007/s10584-012-0424-6

D’Ambrosio, U. (2007). Peace, social justice, and ethnomathematics. In B. Sriraman (Ed.), International perspectives on social justice in mathematics education (pp. 37-50). Information Age.

Frisch, M. (2018). Modeling climate policies: The social cost of carbon and uncertainties in climate predictions. In E. A. Lloyd \& E. Winsberg (Eds.), Climate modelling: Philosophical and conceptual issues (pp. 413-448). Springer. https://doi.org/10.1007/9783-319-65058-6_14

Funtowicz, S., \& Ravetz, J. (2003, February). Post-normal science. In Internet encyclopedia of ecological economics. International Society for Ecological Economics. http://isecoeco.org/pdf/pstnormsc.pdf

Funtowicz, S., \& Ravetz, J. (2008). Values and uncertainties. In G. H. Hadorn, H. Hoffmann-Riem, S. Biber-Klemm, W. Grossenbacher-Mansuy, D. Joye, C. Pohl, U. Wiesmann, \& E. Zemp (Eds.), Handbook of transdisciplinary research (pp. 361-368). Springer. https://doi.org/10.1007/978-1-4020-6699-3_23

Gutstein, E. (2012). Reading and writing the world with mathematics: Toward a pedagogy for social justice. Routledge. https://doi.org/10.4324/9780203112946

Hamlin, L. (2016, May 25). Climate models don't work. Watts Up With That? https://wattsupwiththat.com/2016/05/25/climate-models-dont-work/

Hauge, K. H., \& Barwell, R. (2017). Post-normal science and mathematics education in uncertain times: Educating future citizens for extended peer communities. Futures, 91, 25-34. https://doi.org/10.1016/j.futures.2016.11.013 
Hijmans, R. J., Cameron, S., Parra, J., Jones, P., Jarvis, A., \& Richardson, K. (2010, May 8). WorldClim: Global weather stations. Data Basin. https://databasin.org/datasets/ 15a31dec689b4c958ee491ff3 ofcce 75

Intergovernmental Panel on Climate Change. (2001). Climate change 2001: The scientific basis. Cambridge University Press. https://www.ipcc.ch/site/assets/ uploads/2018/o7/WG1_TAR_FM.pdf

Intergovernmental Panel on Climate Change. (2013). Climate change 2013: The physical science basis. Cambridge University Press. http://www.climatechange2013.org/ images/report/WG1AR5_ALL_FINAL.pdf

Intergovernmental Panel on Climate Change. (2018a). Global warming of $1.5^{\circ} \mathrm{C}$. https://www.ipcc.ch/sri5/

Intergovernmental Panel on Climate Change. (2018b, October 8). Summary for policymakers of IPCC special report on global warming of $1.5^{\circ} \mathrm{C}$ approved by governments. https://www.ipcc.ch/2018/10/o8/summary-for-policymakers-of-ipcc-special-reporton-global-warming-of-1-5c-approved-by-governments/

Kingan, S. (2005). Rethinking and connecting algebra to real-world issues. In E. Gutstein \& B. Peterson (Eds.), Rethinking mathematics: Teaching social justice by the numbers (pp. 238-242). Rethinking Schools.

Lloyd, E. A. (2018). The role of "complex" empiricism in the debates about satellite data and climate models. In E. A. Lloyd \& E. Winsberg (Eds.), Climate modelling: Philosophical and conceptual issues (pp. 137-173). Springer. https://doi.org/10.1007/978-3319-65058-6_6

Lloyd, E. A., \& Winsberg, E. (2018). Introduction. In E. A. Lloyd \& E. Winsberg (Eds.), Climate modelling: Philosophical and conceptual issues (pp. 1-28). Springer. https://doi.org/10.1007/978-3-319-65058-6_1

Mann, M. E., Rahmstorf, S., Steinman, B. A., Tingley, M., \& Miller, S. K. (2016). The likelihood of recent record warmth. Scientific Reports, 6, 1-7. https://doi.org/10.1038/ srep19831

Ministry of Education and Research. (2013, June 21). Curriculum for the common core subject of mathematics. http://data.udir.no/klo6/MAT1-04.pdf?lang= http://data.udir.no/klo6/eng

Nordén, B. (2018). Transdisciplinary teaching for sustainable development in a whole school project. Environmental Education Research, 24(5), 663-677. https://doi.org/ 10.1080/13504622.2016.1266302

Nuccitelli, D. (2016, February 19). Republicans' favorite climate chart has some serious problems. The Guardian. https://www.theguardian.com/environment/climateconsensus-97-per-cent/2016/feb/19/republicans-favorite-climate-chart-has-someserious-problems

Organisation for Economic Co-operation and Development. (2015). Intervention and research protocol for OECD project on assessing progression in creative and critical 
thinking skills in education. http://www.oecd.org/education/ceri/EDU-CERI-CD2015-12-REV1.pdf

Organisation for Economic Co-operation and Development. (2016). PISA 2015 assessment and analytical framework: Science, reading, mathematic and financial literacy. https://doi.org/10.1787/9789264255425-en

Oreskes, N. (2018). The scientific consensus on climate change: How do we know we're not wrong? In E. A. Lloyd \& E. Winsberg (Eds.), Climate modelling: Philosophical and conceptual issues (pp. 31-64). Springer. https://doi.org/10.1007/978-3-319-65058-6_2

Santer, B. D., Thorne, P. W., Haimberger, L., Taylor, K. E., Wigley, T. M. L., Lanzante, J. R., Solomon, S., Free, M., Gleckler, P. J., Jones, P. D., Karl, T. R., Klein, S. A., Mears, C., Nychka, D., Schmidt, G. A., Sherwood, S. C., \& Wentz, F. J. (2008). Consistency of modelled and observed temperature trends in the tropical troposphere. International Journal of Climatology, 28(13), 1703-1722. https://doi.org/10.1002/joc.1756

Schmidt, G. (2016, May 7). Comparing models to the satellite datasets. Real Climate. http://www.realclimate.org/index.php/archives/2016/o5/comparing-models-tothe-satellite-datasets/\#more-18943

Sherrington, G. H. (2018, December 20). The climate sciences use of the urban heat island effect is pathetic and misleading. Watts Up With That? https://wattsupwiththat.com/ 2018/12/20/the-science-of-the-urban-heat-island-effect-is-pathetic-and-misleading/

Skovsmose, O. (1994). Towards a philosophy of critical mathematics education. Kluwer. https://doi.org/10.1007/978-94-017-3556-8

Skovsmose, O. (2014). Critical Mathematics Education. In S. Lerman (Ed.), Encyclopedia of mathematics education (pp. 116-120). Springer. https://doi.org/10.1007/97894-007-4978-8

Steffensen, L. (2021). Critical mathematics education and climate change. A teaching and research partnership in lower-secondary school (Doctoral dissertation). Western Norway University of Applied Sciences.

Steffensen, L., Herheim, R., \& Rangnes, T. E. (2018). Wicked problems in school mathematics. In E. Bergqvist, M. Österholm, C. Granberg, \& L. Sumpter (Eds.), Proceedings of the 42nd Conference of the International Group for the Psychology of Mathematics Education (Vol. 4, pp. 227-234). PME.

Stroeve, J. C., Kattsov, V., Barrett, A., Serreze, M., Pavlova, T., Holland, M., \& Meier, W. N. (2012). Trends in Arctic sea ice extent from $\mathrm{CMIP}_{5}, \mathrm{CMIP}_{3}$ and observations. Geophysical Research Letters, 39(16), 1-7. https://doi.org/10.1029/2012GL052676

Vithal, R. (2003). In search of a pedagogy of conflict and dialogue for mathematics education. Springer. https://doi.org/10.1007/978-94-010-0o86-4

Watts, A. (2017). Global temperatures plunge in April - "The pause" returns. Watts Up With That? https://wattsupwiththat.com/2017/05/o1/global-temperatures-plungein-april-the-pause-returns/ 